\title{
KAJIAN PENGARUH KEBAKARAN TERHADAP SIFAT KARAKTERISTIK BATA BETON GEOPOLIMER DARI FLY ASH DAN BOTTOM ASH LIMBAH PLTU TANJUNG JATI
}

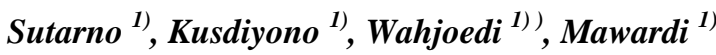 \\ 1) Jurusan Teknik Sipil Politeknik Negeri Semarang \\ Jln. Prof. Soedarto, SH, Tembalang, Semarang, 50275 \\ Email: sutarno@polines.ac.id, kusdiyono@polines.ac.id,wahjoedi@polines.ac.id
}

\begin{abstract}
ABSTRAK
Bata beton geopolimer adalah batu bata beton yang pembuatannya menggunakan mortar geopolimer. Bata beton geopolimer yang dikaji dibuat dengan memanfaatkan botom ash sebagai agregat pengisi dan fly ash sebagai perekat pengganti semen yang direaksikan dengan $\mathrm{NaOH}$ dan $\mathrm{Na} \mathrm{SiO}_{2}$ hingga terjadi polimerisasi yang memiliki sifat merekat. Disisi lain PLTU Tanjung jati merupakan pembangkit listrik cukup besar, menghasilkan limbah sisa pembakaran batu bara sebagai bahan energi berupa fly ash dan botom ash. Tiap hari volume limbah berupa fly ash dan bottom ash di PLTU Tanjung Jati kurang lebih 1.000 ton perhari dan limbah ini tergolong limbah B3. Upaya mengatasi masalah limbah fly ash dan bottom ash, salah satu alternatif yang di kaji dengan dibuat Bata geopolimer. Fly Ash dimanfaatkan sebagai bahan pengikat dan botom ash sebagai bahan pengisi, fly ash direaksikan dengan $\mathrm{NaOH}$ dan $\mathrm{Na} \mathrm{SiO}_{2}$. menjadi binder kemudian ditambahkan bottom ash kemudian dicetak menjadi benda uji bata beton geopolimer. Bata sebagai benda uji dibuat dengan komposisi; 1 binder : 3 agregat dan 1 binder : 4 agregat, sedangkan untuk bindernya ada 2 variasi yaitu 16 molar dan 18 molar. Benda uji setelah mengeras dengan umur 28 hari kemudian dibakar dengan durasi pembakaran selama 1 jam, 2 jam, 3 jam dan 4 jam, setelah proses pembakaran dilanjutkan dengan uji kuat tekan, uji kembang susut volume, dan uji perubahan bobot isi, simpulan dari hasil analisis yang dilakukan adalah: Kuat tekan maximum terjadi pada binder $18 \mathrm{M}$ dengan campuran 1 Fs : 3 Ba memiliki kekuatan $83,5 \mathrm{Kg} / \mathrm{cm}^{2}$; Terjadi peningkatan kuat tekan akibat pembakaran pada semua tipe campuran; Pada campuran 1 fs: 3 Ba peningkatan kuat tekan maximum terjadi pada pembakaran 2 jam dan untuk campuran $1 \mathrm{fs}: 4 \mathrm{Ba}$ terjadi peningkatan kuat tekan maximum pada pembakaran selama 1 jam; Tidak ada beda bobot isi benda uji akibat pembakaran untuk semua jenis campuran; Terjadi pengembangan dan retak retak akibat pembakaran.
\end{abstract}

Kata kunci: fly ash, bottom ash, batu bata, beton geopolimer.

\section{PENDAHULUAN}

\section{Latar Belakang}

Tumbuhnya industri dan jumlah penduduk akan diikuti tambahnya bebutuhan energi listrik. Keberadaan PLTU Tanjung Jati merupakan jawaban fenomena tersebut terutama untuk kebutuhan listrik wilayah Jawa, Bali, Madura.

PLTU Tanjung Jati memakai bahan bakar batubara sebagai sumber energinya, maka limbah yang dihasilkan berupa Fly Ash dan Bottom Ash, Tiap hari volume limbah batubara yang dibuang (keluar area PLTU TJB) kurang lebih 1.000 ton perhari. Limbah ini jika tidak ada rencana penanganan yang baik, kemungkinan PLTU bisa berhenti operasional, demikian pernyataan I Dewa Gede Ngurah Ambara, General Manager PLTU TJB (suaramerdeka.com, Suara Muria, 21 Maret 2013). 
Di dalam Peraturan Pemerintah (PP. No. 85 tahon 1999), yang berisi tentang pengelolaan limbah bahan berbahaya dan beracun (B3), Fly ash dan bottom ash dikategorikan limbah B3 karena mengandung logam berat, sehingga tidak boleh dibuang begitu saja karena dapat terjadi proses pelindihan secara alami dan akan mencemari lingkungan sehingga berbahaya bagi kesehatan masyarakat.

Telah menjadi tanggung jawab bersama bahwa mengurangi emisi $\mathrm{CO}_{2}$ dan pemanasan global harus disadari dan diupayakan demi kelestarian alam, saat ini telah banyak dilakukan penelitian yang mengarah pada pengembangan "beton hijau" atau beton ramah lingkungan dengan mengurangi atau bahkan tanpa memakai semen portland dalam pembuatannya, dikenal dengan beton geopolimer. Beton Geopolimer pertama kali dikembangkan oleh Davidovits di tahun 1978, yaitu beton dengan pengikat dari polimer hasil reaksi alkali silika dan alumina yang terkandung dari material geologi seperti fly ash, blast furnance slag, metakaolin atau abu sekam padi. (Dany Cahyadi, 2013)

Selama periode Januari 2019 sebanyak 18 kejadian kebakaran telah berlangsung di Kota Semarang, dan kecamatan Semarang Utara menjadi daerah yang paling banyak mengalami kebakaran dengan lima kejadian. (Suara Merdeka.com, 29 Januari 2019).

Berdasarkan uraian di atas, bata beton geopolimer dengan bahan bakunya bottom ash yang nantinya dipakai sebagai dinding bangunan maka perlu dipastikan perilaku karakteristiknya akibat pengaruh kebakaran, mengingat kemungkinan limbah bottom ash belum terbakar sempurna.

\section{Tujuan Penelitian}

Tujuan penelitian adalah terwujudnya batu bata geopolimer dari limbah PLTU Tanjung Jati yang siap diproduksi disertai dengan jaminan karakteristik bata yang telah dikaji sehingga diketahui kualitasnya terutama pengaruh pembakaran terhadap kuat tekan bata, bobot isi.

\section{TINJAUAN PUSTAKA}

Beberapa hal yang perlu disampaikan sehubungan dengan bahan yang digunakan dalam penelitian antara lain;

\section{Bata Geopolimer}

Bata geopolimer yang di kaji adalah bata beton yang dibuat dari bahan mortar geopolimer, yaitu mortar yang metode pengikatannya menggunakan metode polimerisasi dari bahan dasar fly ash limbah PLTU Tanjung Jati dengan direaksikan menggunakan $\mathrm{NaOH}$ dan $\mathrm{Na} \mathrm{SiO}_{2}$. Kemudian ditambah dengan bottom ash sebagai agregat halus.

\section{Fly Ash}

Batu bara sebagai bahan bkar PLTU menyebabkan masalah serius terhadap lingkungan. Limbah yang dihasilkan dapan berupa fly ash, bottom ash dan gipsum yang selama ini di tumpuk pada gudang limbah. Salah satu solusi penggunaan Fly ash adalah sebagai material stabilisasi sub base jalan di sekitar lokasi. Suatu struktur perkerasan jalan setelah dilaksankan akan mengalami perubahan musim pengujan dan kemarau. Pada musim penghujan 
lapis sub base akan mengalami genangan air merupakan masalah yang harus diatasi (Arief Subakti Ariyanto, 2017). Fly ash dan bottom ash merupakan limbah padat dihasilkan sisa pembakaran batubara pada pembangkit listrik tenaga uap atau proses industri lainnya. Limbah padat ini terdapat dalam jumlah yang relatif besar, sehingga memerlukan pengelolaan yang serius agar tidak menimbulkan masalah pencemaran lingkungan, seperti pencemaran udara, perairan dan penurunan kualitas ekosistem lainnya. Fly Ash merupakan material dengan butiran sangat halus, berwarna keabu abuan, diperoleh dari sisa pembakaran batu bara (Kusdiyono, 2017). Fly Ash mengandung unsur kimia antara lain Silica $\left(\mathrm{SiO}_{2}\right)$, Alumina $\left(\mathrm{Al}_{2} \mathrm{O}_{3}\right)$, Fero Oksida $\left(\mathrm{Fe}_{2} \mathrm{O}_{3}\right)$, dan Calsium Oksida $(\mathrm{CaO})$. Menurut (ASTM. C 618-94a) Fly Ash dibagi dalam tiga kelas: kelas $\mathrm{N}$, kelas F dan kelas $\mathrm{C}$.

Pada penelitian ini menggunakan fly ash dari PLTU Tanjung Jati dari hasil analisis laboratorium dengan menggunakan citra SEM dengan analisis EDX memiliki komposisi kandungan senyawa sebagai berikut:

Tabel 1. Karakteristik Kimia Limbah Fly Ash PLTU Tanjung Jati B Jepara

\begin{tabular}{cclr}
\hline No & $\begin{array}{c}\text { Nama } \\
\text { Sampel }\end{array}$ & Komponen & $\begin{array}{c}\text { Komposisi } \\
\text { (\% berat) }\end{array}$ \\
\hline 1 & Fly Ash & Karbon, C & 22,13 \\
& & Natrium & 2,04 \\
& & Oksida, $\mathrm{Na}_{2} \mathrm{O}$ & \\
& & Magnesium & 2,8 \\
& & Oksida, $\mathrm{MgO}$ & \\
& & Alumina, & 17,08 \\
& $\mathrm{Al}_{2} \mathrm{O}_{3}$ & \\
& $\mathrm{Silika}$ & 36,79 \\
& Dioksida, $\mathrm{SiO}_{2}$ & \\
\cline { 2 - 3 } & Sulfat, $\mathrm{SO}_{3}$ & 1,09 \\
& Kalium & 1,45 \\
\hline
\end{tabular}

\begin{tabular}{|c|c|}
\hline Oksida, $\mathrm{K}_{2} \mathrm{O}$ & \\
\hline Kalsium & 5,52 \\
\hline Oksida, $\mathrm{CaO}$ & \\
\hline Titanium & 0,78 \\
\hline Dioksida $\mathrm{TiO}_{2}$ & \\
\hline Besi Oksida, & 9,29 \\
\hline $\mathrm{FeO}$ & \\
\hline Tembaga & 1,05 \\
\hline Oksida, $\mathrm{CuO}$ & \\
\hline
\end{tabular}

Data hasil pengujian Lab. Terpadu UNDIP, Sutarno, 2017

Dari hasil uji laboratorium maka menurut ASTM C 618, Fly Ash limbah PLTU Tanjung Jati B Jepara tergolong pozzoland kelas $\mathrm{N}$ dan $\mathrm{F}$, memiliki kandungan $\left(\mathrm{SiO}_{2}\right.$ dan $\mathrm{Al}_{2} \mathrm{O}_{3}$ ) cukup tinggi, dan mengingat pengerasan geopolimer adalah terjadinya reaksi polikondensasi $\mathrm{SiO}_{2}$ dan $\mathrm{Al}_{2} \mathrm{O}_{3}$ maka Fly Ash PLTU Tanjung Jati $\mathrm{B}$ sangat baik untuk bahan bata geopolimer.

\section{Bottom Ash}

Batubara merupakan bahan bakar yang banyak digunakan di PLTU. Pembakaran batubara akan menghasilkan limbah padat Partikel abu yang terbawa gas buang disebut abu terbang (fly ash), sedangkan abu yang tertinggal dan dikeluarkan dari bawah tungku disebut abu dasar (bottom ash). Sebagian besar abu terbang dan abu dasar dikumpulkan dalam pembuangan abu (ash disposal).

Kandungan senyawa kimia pada Bottom Ash di dominasi oleh senyawa silica dan alumina, sebagai pembanding yang dilakukan Achmad Freddyan, dkk, 2015 adalah sebagai berikut; 
Tabel 2. Hasil Analisis XRF Bottom Ash

\begin{tabular}{cc}
\hline Senyawa & \% \\
\hline $\mathrm{SiO}_{2}$ & 39.96 \\
$\mathrm{Al}_{2} \mathrm{O}_{3}$ & 44.56 \\
$\mathrm{Fe}_{2} \mathrm{O} 3$ & 2.34 \\
$\mathrm{SO}_{3}$ & 0.58 \\
$\mathrm{CaO}$ & 1.67 \\
\hline $\mathrm{MgO}$ & 5.04 \\
$\mathrm{Na}_{2} \mathrm{O}$ & 0.46 \\
$\mathrm{~K}_{2} \mathrm{O}$ & 0.26 \\
$\mathrm{P}_{2} \mathrm{O}_{5}$ & 1.11 \\
\hline Data dari Achmad Freddya Eka \\
Prasandha, ITS, 2015.
\end{tabular}

\section{Natrium Hidroksida ( $\mathrm{Na} \mathbf{O H}$ )}

$\mathrm{Na} \mathrm{OH}$ adalah larutan alkalin yang digunakan dalam pembuatan geopolimer adalah logam alkali yang larut. Logam alkali yang sering digunakan rebagai reagen pada reaksi geopolimerisasi adalah Natrium $(\mathrm{Na})$ dan Kalium ( $\mathrm{K}$ ). Massa molekul relatif $\mathrm{NaOH}$ adalah 40 gram $/ \mathrm{mol}$. Natrium hidroksida dapat mengabsorbsi $\mathrm{CO}_{2}$ dari udara, sangat korosif pada logam alumunium. Natrium Hidroksida menghasilkan panas (eksotermis) saat dilarutkan dalam air atau ketika dilarutkan dengan asam. $\mathrm{NaOH}$ berbentuk pelet dapat mencapai kemurnian 97-98\% (Windholtz, 1976. dalam Niken Swastika 2010).

\section{Natrium Silikat ( Waterglass )}

Komposisi Natrium Silikat (Waterglass) saat kering adalah $\mathrm{Na}_{2} \mathrm{SiO}_{3}, \quad \mathrm{Na}_{6} \mathrm{SiO}_{7}, \mathrm{Na}_{2} \mathrm{Si}_{3} \mathrm{O}_{7}$ dengan komposisi air yang bervariasi. Bentuknya bening sampai putih atau putih keabu abuan, kristalin atau seperti lem. Natrium silikat juga dapat mengiritasi kulit. Natrium silikat dalam bentuk larutannya adalah alkalin kuat (Windholtz, 1976. dalam Niken Swastika 2010).

\section{METODE PENELITIAN}

Pelaksanaan penelitian dibagi dalam beberapa tahap yaitu tahap persiapan, pembuatan activator, pembuatan binder, pengadukan beton geopolimer, pencetakan benda uji, perawatan benda uji, pembakaran lalu pengujian. Uji yang dilakukan kuat tekan dan bobot isi, dari hasil uji kemudian dilakukan analisis data, untuk jelasnya dapat dilihat dalam flow chart jalannya penelitian sebagai berikut.

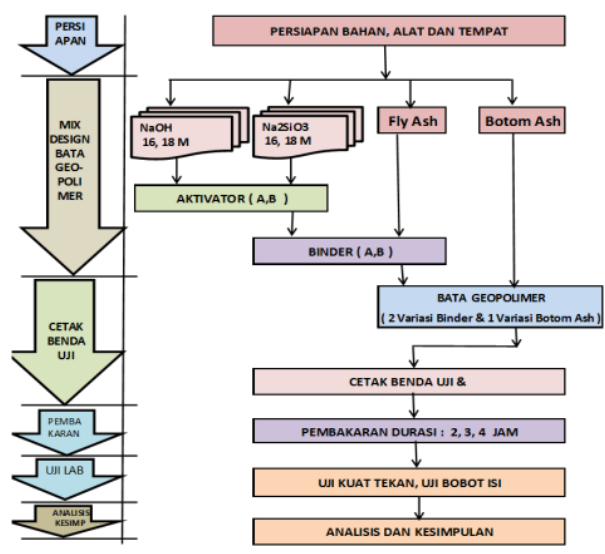

Gambar 1. Diagram jalannya pelaksanaan penelitian.

\section{Benda Uji}

tahapan Pencampuran dan pengadukan bahan dengan berbagai komposisi dan variasi sesuai yang direncanakan sebagai berikut:

\section{Binder}

Binder ada dua variabel yaitu binder A dengan kepekatan aktivator 16 molar dan binder B dengan kepekatan aktivator 18 molar, binder dibuat dengan perbandingan berat antara activator dengan fly ash 2 berbanding 5 (perbandingan berat). 
Tabel 3. Komposisi Binder

\begin{tabular}{ccc}
\hline Binder & Aktivator & Fly Ash \\
\hline \multirow{2}{*}{ A } & $2\left(\mathrm{NaOH}, \mathrm{Na} \mathrm{SiO}_{2}\right.$, & 5 Fly \\
& $16 \mathrm{M})$ & ash \\
B & $2\left(\mathrm{NaOH}, \mathrm{Na} \mathrm{SiO}_{2}\right.$, & $5 \mathrm{Fly}$ \\
& $18 \mathrm{M})$ & ash \\
\hline
\end{tabular}

\section{Komposisi Campuran Benda Uji}

Benda uji untuk kuat tekan terdapat 4 variasi sebagai variabel adalah sebagai berikut; Sampel tipe 1 adalah benda uji dengan komposisi campuran menggunakan binder tipe A dengan komposisi fly ash : bottom ash sebesar 1: 3 (perbandingan berat). Sampel tipe 2 adalah benda uji dengan komposisi camporan menggunakan binder tipe A dengan komposisi fly ash : bottom ash sebesar 1:4 (perbandingan berat). Sampel tipe 3 adalah benda uji dengan komposisi camporan menggunakan binder tipe $\mathrm{B}$ dengan komposisi fly ash : bottom ash sebesar 1:3 (perbandingan berat). Sampel tipe 4 adalah benda uji dengan komposisi campuran menggunakan binder tipe $\mathrm{B}$ dengan komposisi fly ash : bottom ash sebesar 1:4 (perbandingan berat).

Tabel 4. Komposisi Campuran Benda

\begin{tabular}{ccc}
\multicolumn{3}{c}{ Uji } \\
\hline $\begin{array}{c}\text { Tipe } \\
\text { Campuran }\end{array}$ & $\begin{array}{c}\text { Tipe } \\
\text { Binder }\end{array}$ & Campuran \\
\hline 1 & $\mathrm{~A}$ & $1: 3$ \\
2 & $\mathrm{~A}$ & $1: 4$ \\
3 & $\mathrm{~B}$ & $1: 3$ \\
4 & $\mathrm{~B}$ & $1: 4$ \\
\hline
\end{tabular}

\section{Pengujian}

Benda Uji berbentuk Kubus ukuran 5 X 5 X $5 \mathrm{~cm}$. dan pengujian kuat tekan dengan metode "Compressive Strength of Cube Concrete Specimens" (ASTM C 39 -
94), penghitungan hasil dengan formula sebagai berikut;

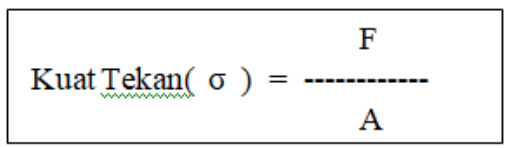

Dimana : $\quad \mathrm{F}=$ Beban Maximum ( Kgf ) dan A = Luas penampang yang tertekan $\left(\mathrm{cm}^{2}\right)$.

\section{HASIL DAN PEMBAHASAN}

\section{Hasil Uji Kuat Tekan}

Dari hasil analisis dapat diketahui bahwa kuat tekan maksimum terjadi pada campuran dengan moralitas $18 \mathrm{M}$ di campuran 1Fs : 3 Ba yaitu sebesar $83.5 \mathrm{Kg} / \mathrm{Cm}^{2}$ dan tidak selisih jauh untuk campuran $1 F s \quad: \quad 4 \quad \mathrm{Ba}$ yaitu sebesar 80.4 $\mathrm{Kg} / \mathrm{Cm}^{2}$.

Dari semua jenis campuran dapat diketahui mengalami peningkatan kekuatan akibat pembakaran, untuk campuran 1Fs : 3 $\mathrm{Ba}$, binder $18 \mathrm{M}$ peningkatan maximum terjadi pada pembakaran 2 jam namun pembakaran sampai 3 dan 4 jam kekuatannya turun setara dengan sebelum dibakar. Untuk campuran $1 \mathrm{Fs}: 3 \mathrm{Ba}$, binder $16 \mathrm{M}$ peningkatan maximum terjadi pada pembakaran 1 jam namun pembakaran sampai 2, 3 dan 4 jam kekuatannya turun hingga setara dengan sebelum dibakar. Untukcampuran 1Fs : $4 \mathrm{Ba}$, binder 18 $\mathrm{M}$ dan $16 \mathrm{M}$ mengalami perubahan kuat tekan yang sama yaitu terjadi peningkatan max pada pembakaran 1 jam kemudian berangsur turun sampai pembakaran 4 jam kekuatannya kembali setara sebelum dibakar 


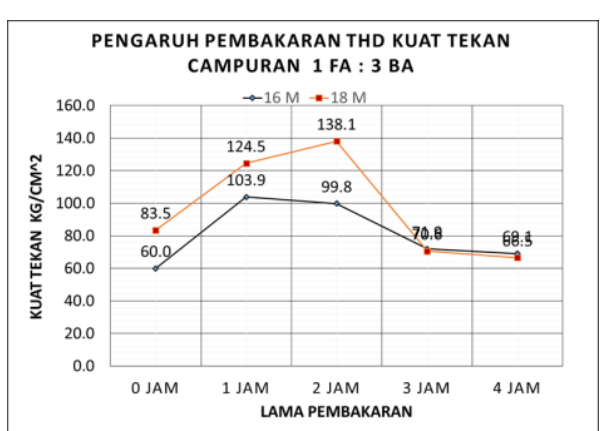

Grafik 1. Pengaruh Pembakaran

Terhadap Kuat Tekan Campuran. 1Fa : $3 \mathrm{Ba}$.

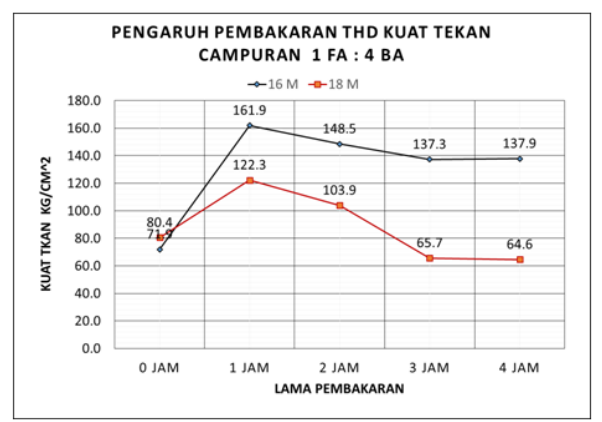

Grafik 2. Pengaruh Pembakaran Terhadap Kuat Tekan Campuran 1Fa : $4 \mathrm{Ba}$

\section{Hasil Uji Muai Susut akibat Pembakaran}

Bata beton geopolimer mengalami pemuaian tetap akibat pembakaran, dan laju pemuaian besar tejadi pada pembakaran sampai 1 jam kemudian pemuaian masih bertambah sedikit sampai pembakaran 4 jam.

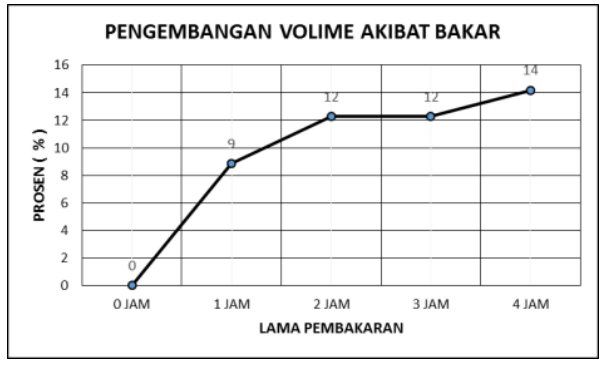

Grafik 3. Pengaruh Pembakaran Terhadap Pengembangan volume

\section{Hasil Uji Susut Berat Akibat Pembakaran}

Dari Uji pembakaran terhadap Bata Beton Geopolimer ternyata penyusutan pada beratnya, akan tetapi terbukti tidak ada beda penyusutan untuk semua jenis campuran maupun akibat lama pembakaran, penyusutan berat terjadi rata-rata sebesar $11 \%$.

Tabel 4. Pengaruh Pembakaran Terhadap Susut Berat

\begin{tabular}{|c|c|c|c|c|c|c|}
\hline $\begin{array}{c}\text { Waktu } \\
\text { bakar (jam) }\end{array}$ & $\begin{array}{c}\text { Molar } \\
\text { itas }\end{array}$ & Campuran & $\begin{array}{c}\text { Berat belum } \\
\text { bakar (gr) }\end{array}$ & $\begin{array}{c}\text { Berat sudah } \\
\text { bakar (gr) }\end{array}$ & $\begin{array}{c}\begin{array}{c}\text { Susut } \\
\text { berat (gr) }\end{array} \\
\text { bet }\end{array}$ & $\begin{array}{c}\text { Susut } \\
\text { berat }(\%)\end{array}$ \\
\hline \multirow[t]{4}{*}{0} & 16 & $1: 3(\mathrm{I})$ & 204 & 204 & 0 & 0 \\
\hline & & $1: 4$ (II) & 207 & 207 & 0 & 0 \\
\hline & 18 & 1:3 (III) & 213 & 213 & 0 & 0 \\
\hline & & $1: 4$ (IV) & 198 & 198 & 0 & 0 \\
\hline \multirow[t]{4}{*}{1} & 16 & $1: 3(\mathrm{I})$ & 195 & 179 & 16 & 8 \\
\hline & & $1: 4$ (II) & 208 & 187 & 21 & 10 \\
\hline & 18 & 1:3 (III) & 215 & 189 & 26 & 12 \\
\hline & & $1: 4$ (IV) & 204 & 179 & 15 & 12 \\
\hline \multirow[t]{4}{*}{2} & 16 & $1: 3$ (I) & 197 & 181 & 16 & 8 \\
\hline & & $1: 4$ (II) & 204 & 181 & 23 & 11 \\
\hline & 18 & 1:3 (III) & 213 & 187 & 26 & 12 \\
\hline & & $1: 4$ (IV) & 209 & 183 & 26 & 12 \\
\hline \multirow[t]{4}{*}{3} & 16 & $1: 3$ (I) & 207 & 191 & 16 & 8 \\
\hline & & $1: 4$ (II) & 207 & 185 & 22 & 11 \\
\hline & 18 & $1: 3$ (III) & 212 & 185 & 27 & 13 \\
\hline & & $1: 4$ (IV) & 202 & 178 & 24 & 12 \\
\hline \multirow[t]{4}{*}{4} & 16 & $1: 3$ (I) & 211 & 191 & 20 & 9 \\
\hline & & $1: 4$ (II) & 207 & 186 & 21 & 10 \\
\hline & 18 & 1:3 (III) & 212 & 185 & 27 & 13 \\
\hline & & $1: 4$ (IV) & 205 & 180 & 25 & 12 \\
\hline
\end{tabular}

\section{Gambar Pengujian}
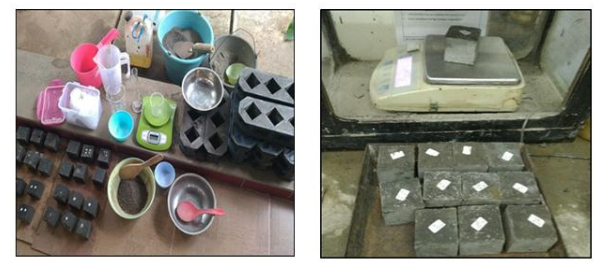

Foto 1. Buat Benda Uji dan Foto 2. Uji Bobot Isi
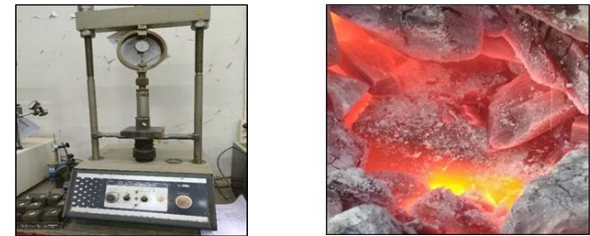

Foto 3. Uji Kuat Tekan dan Foto 4. Uji Bakar 


\section{SIMPULAN}

1. Kuat tekan meningkat setelah mengalami pembakaran satu sampai 2 jam dan kembali pada kuat tekan semula pada pembakaran 3 sampai 4 jam.

2. Benda uji mengalami pemuaian sebesar $9 \%$ pada pembakaran selama 1 jam dan $12 \%$ pada pembakaran 2 dan 3 jam serta $14 \%$ pada pembakaran 4 jam.

3. Benda Uji mengalami penyusutan berat sebesar $11 \%$ pada pembakaran 1,2, 3 dan 4 Jam.

4. Akibat pembakaran secara visual permukaan benda uji terlihat retak - retak halus.

5. Bahan bata dari Fly Ash dan Bottom Ash dengan pengikatan secara geopolimer sangat baik untuk bahan bangunan karena tergolong material tidak mudah terbakar dan tidak terjadi penurunan kuat tekan akibat pembakaran.

\section{DAFTAR PUSTAKA}

PLTU Tanjung Jati B Ramah Lingkungan, suaramerdeka.com. 21 Maret 2013.

Ariyanto, Arief Subakti. 2017. Pengaruh Durabilitas Terhadap Stabilisasi Sub Base Jalan Dengan Fly Ash Dari Pltu Asam Asam Kalimantan Selatan. Bangun Rekaprima: Majalah Ilmiah Pengembangan Rekayasa, Sosial dan Humaniora, 3 (1, April). Semarang: Politeknik Negeri Semarang.
Cahyadi, Dany. 2013. Sifat Mekanik dan Durabilitas Polypropylene Fiber Reinforced Geopolymer Concrete. Jurnal Teknik Sipil. Surakarta: Universitas Sebelas Maret.

Kusdiyono, Tedjo Mulyono \& Supriyadi. 2017. Pengaruh Penambahan Fly Ash Dan Bottom Ash Terhadap Mutu Paving. Bangun Rekaprima: Majalah Ilmiah Pengembangan Rekayasa, Sosial dan Humaniora, 3 (2, Oktober). Semarang: Politeknik Negeri Semarang.

Niken Swastika, 2010. Analisis Ketahanan Beton Geopolimer Berbahan Abu Terbang dan Berbahan Metakaolin Terhadap Paparan Air Laut ASTM. Fakultas Teknik Jakarta: Universitas Indonesia.

Peraturan Pemerintah Republik Indonesia Nomor 85 Tahun 1999. Perubahan Atas Peraturan Pemerintah Republik Indonesia Nomor 18 Tahun $1999 \quad$ Tentang Pengelolaan Limbah Berbahaya dan Beracun. 7 Oktober 1999. Lembaran Negara Republik Indonesia Tahun 1999. Jakarta.

Prasanda, Achmad Fredya Eka. 2015. Paving Geopolimer Berbahan Dasar Bottom Ash dan Sugar Cane Bagasse Ash (SCBA). Jurnal Teknik Sipil ITS. Vol. 4, No. 2, ISSN: $2337-3539$, Surabaya: Institut Teknologi Surabaya. 
Sutarno. 1999. Kajian Efek Abu Terbang Sebagai Bahan Pengganti Sebagian Semen.
Jurusan Teknik Sipil. Semarang: Politeknik Negeri Semarang. 